\author{
Military Technical College \\ Kobry El-Kobbah, \\ Cairo, Egypt
}

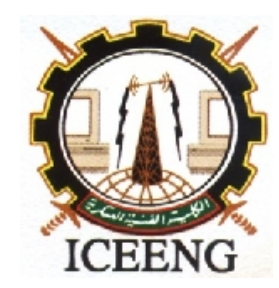

\title{
Impact of Midpoint SVC on the Generator Distance Phase Backup Protection
}

\author{
By \\ M. Elsamahy $* \quad$ S.O. Faried, $* * \quad$ T.S. Sidhu $* * * \quad$ G. Ramakrishna**
}

\section{$\underline{\text { Abstract: }}$}

In this paper, investigations are carried out to explore the impact of a midpoint SVC on the performance of the generator distance phase backup protection (function 21). The results of these investigations have shown that the midpoint SVC has an adverse effect on such protection. Such an impact varies according to the fault type, the fault location, and the generator loading. The dynamic simulations of a test benchmark have been conducted using the PSCAD/EMTDC software.

\section{Keywords:}

Generator distance phase backup protection, Static Var Compensator (SVC).

* Egyptian Armed Forces

** Department of Electrical and Computer Engineering, University of Saskatchewan, Saskatoon, SK, S7N 5A9, Canada (e-mails: sherif.faried@mail.usask.ca, rama.krishna@mail.usask.ca).

*** Department of Electrical and Computer Engineering, University of Western Ontario, London, ON N6A 5B9, Canada (e-mail: Sidhu@eng.uwo.ca). 


\section{Introduction:}

Recent misoperations of generating units' protection during major power system disturbances have highlighted the need of secured coordination of generator protection with generator capability, generator control, and transmission system protection.

As a result of recent significant disturbances (1996 outages in the Western U.S. and 2003 U.S. East Coast blackout), the North Electric Reliability Council (NERC) has mandated tests and is demanding from users to verify the coordination between generator protection and generator control. The recent reports of the Working Groups J5 and J-6 of the IEEE Power System Relaying Committee identified the need to improve the coordination between the generator protection and control [1], [2]. More specific, it is necessary to coordinate between the generator protection performance, excitation control, system protection, and other control strategies in order to avoid system collapse. The impact of major disturbances on the performance of generator control and generator protection systems is reported in [3]. It is concluded that a proper coordination of the generator protection relays and excitation control systems is of paramount importance to provide the needed system support during stressed system conditions. An important issue that must be taken into consideration during such coordination is the presence of Flexible AC Transmission System (FACTS) controllers in the power system. This is due to the fact that these controllers can affect the performance of the protective relaying. FACTS controllers provide fast dynamic control of transmission system voltage, currents, impedance and/or phase angles, which are well needed for improvement of reliability and security of power systems. FACTS controllers enhance steady-state stability, transient stability and/or dynamic stability [4], [5]. Furthermore, FACTS controllers can provide an effective countermeasure of subsynchronous resonance oscillations for series capacitive compensated transmission systems. The impact of FACTS controllers on the performance of the protection system varies according to the type of the FACTS controller, the application for which it is used for and its location in the power system. The question of whether the existing transmission line distance protection relays would perform well with the installation of shunt FACTS controllers in the transmission line has been recently investigated and reported in [6]-[12]. The results of these investigations have shown that midpoint shunt FACTS compensation can affect the distance relays with regards to impedance measurement, phase selection and operating times. It has been reported also the observation of the overreaching and underreaching phenomena in the presence of a midpoint shunt FACTS controllers (STATCOM and SVC). As it can be seen from the previous discussion, virtually, no research work has been done until now on the performance of the generator distance phase backup protection in the presence of a midpoint SVC. As the generator distance phase backup relay is in tandem with the transmission line distance relay, the midpoint SVC would definitely have an adverse effect on its performance. 
In this paper, investigations are carried out to explore the impact of a midpoint SVC on the performance of the generator distance phase backup protection. The dynamic simulations of a test benchmark have been conducted using the PSCAD/EMTDC software [13].

\section{Generator Distance Phase Backup Protection:}

A. Function (21) Setting

The function of phase backup protection is to disconnect the generator if a symmetrical or unsymmetrical phase fault outside of the generator zone of protection has not been cleared by other protective devices after a sufficient time delay has elapsed. A mho distance relay with only one zone is commonly used for system phase faults backup. The main goal is to measure the positive sequence impedance from the relay to the fault point where three phase elements are required, $\mathrm{AB}, \mathrm{BC}$, and $\mathrm{CA}$. For setting generator distance phase backup protection with adequate margin overload and stable power swings, the following criteria are applied [14].

- The relay element is typically set at the smallest of the following three criteria:

1. $120 \%$ of the longest line with in-feeds.

2. 50 to $67 \%$ of the generator load impedance $\left(Z_{\text {load }}\right)$ at the rated power factor angle (RPFA) of the generator. This provides a 150 to $200 \%$ margin over generator full load. This is typically the prevailing criteria.

3. 80 to $90 \%$ of the generator load impedance at the maximum torque angle (MTA) of the relay zone setting (typically $\left.85^{\circ}\right)\left(\mathrm{Z}_{\mathrm{GCC}}\right)$.

- The time delay for the relay should be set longer than the transmission lines backup with appropriate margin for proper coordination. For the investigations in this paper, a delay time of 1 second is considered.

In order to achieve a correct operation in terms of satisfying the basic requirements of any protection system, the following considerations must be taken into account:

1. The effect of connecting the generator to the system through a delta-star transformer which introduces a phase shift that may alter the impedance measured by the relay elements.

2. The effect of the infeeds which increases the impedance of the faulted line seen by the distance relay.

3. Attention should be paid to the load at the generator terminals to avoid the misoperation on power system swings.

4. Coordination with transmission line primary and back up protection [14].

\section{Generator Capability Curves}

Protective relaying requires knowledge of the operating range of each component and an understanding of the interactions of the generating unit and the power system. The nameplate ratings of a generator define only one limiting point of operation for the 
machine. It is logical to assume that a reduction in MVAR output would allow some increase in MW output and that a reduction in MW would allow higher MVAR output. These allowable variations are defined by the Generator Capability Curve (GCC), which are provided by the manufacturer [15], [16]. Fig. 1 shows the capability curves for different turbine driven generators. The operating terminal voltage range allowed by standards is $95-105 \%$ of rated voltage, but generator capability curves are normally plotted for rated terminal voltage.

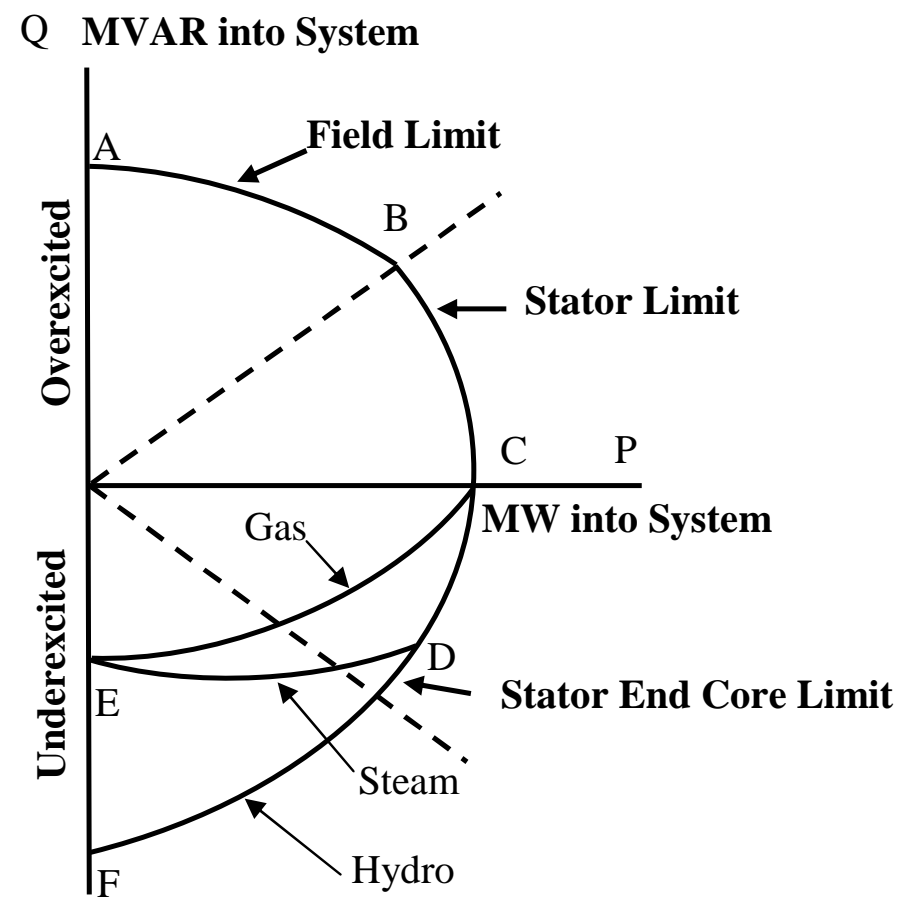

MVAR into Generator

Fig. 1. Generator capability curves for different turbine-driven generators.

The capability curve of a steam turbine driven generator is a composite of three distinct limits. The right-hand section, between $\mathrm{B}$ and $\mathrm{C}$ represents the limit imposed by the ampere rating of the stator winding. The ampere rating of the field winding imposes the limit between A and B, which limits the output VARs to the power system. These are termed "lagging VARs". The bottom limit, C to E for gas turbines or D to E for steam turbines, defines the maximum VARs the generator can consume from the power system. These are termed "leading Vars". This limit is the result of heating in the end laminations of the stator core (Steam/Gas - driven generator). Any determination of leading VAR variation with voltage for use during operations must be determined by the manufacturer. The capability curve for a hydro unit is different from that of a steam unit. Hydro units are of salient pole construction and do not have end core regions. 
Thus, their capability curves have only two distinct limits. The field circuit imposed lagging Vars limit from A to B and the stator winding current limit, which extends as a continuous arc from B to $\mathrm{F}$. The leading VAR limit is determined by the current rating of the stator winding. Generators capability curves are plotted on a P-Q (MW-MVAR) diagram. On the other hand, generator distance phase backup protection (21) measures impedance and the relay characteristics are typically displayed on a ResistanceReactance (R-X) diagram. To coordinate the generator capability with these impedance relays, it is necessary to convert the capability curve to an R-X plot. Fig. 2 illustrates this conversion. The CT and VT ratios $\left(\mathrm{R}_{\mathrm{c}} / \mathrm{R}_{\mathrm{v}}\right)$ convert primary ohms to secondary quantities that are set within the relay and $\mathrm{kV}$ is the rated voltage of the generator [17], [18].

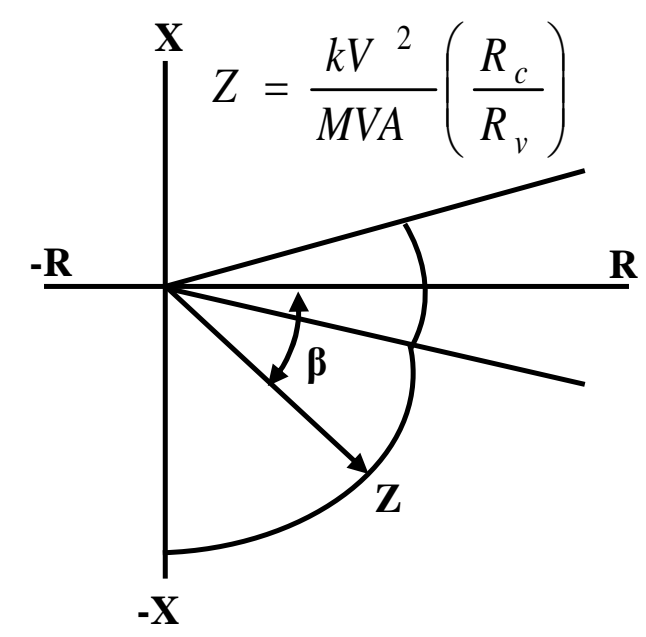

Fig. 2. Transformation of a $P-Q$ plot to an $R-X$ Plot.

\section{System under Study}

The system used in the investigations of this paper is shown in Fig. 3. It consists of a hydro-generator, which is connected via a transformer to an infinite-bus system through a $300 \mathrm{~km}, 230 \mathrm{kV}$ transmission line. A SVC is installed at the middle of the transmission line for the purpose of increasing its power transfer capability. The system data and function 21 relay settings are given in the Appendix. The model used for this study contains the facility to vary the fault location, the fault type, and the loading condition of the generator in order to simulate all possible cases using the PSCAD/EMTDC simulation package. 


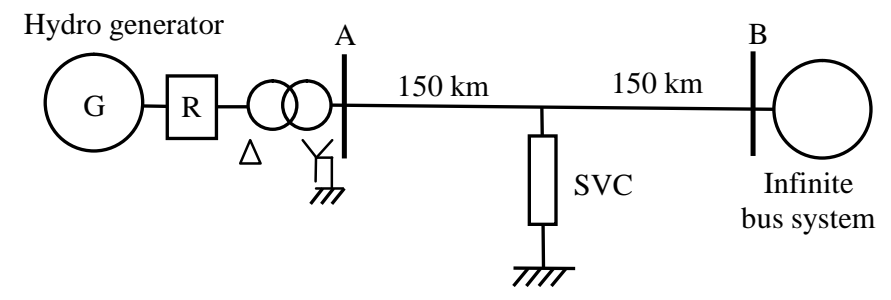

Fig. 3. System under study.

\section{Midpoint SVC in Transmission Lines}

A SVC is essentially composed of thyristor switched capacitor (TSC) and thyristor controlled reactor (TCR) connected in parallel to control the voltage at the point of connection to the power system, by adjusting their susceptances to supply or absorb reactive power. The V-I characteristic of the SVC illustrated in Fig. 4 shows that depending on the operating point, the SVC reactance varies. The slope of the line connecting the operating point and origin.

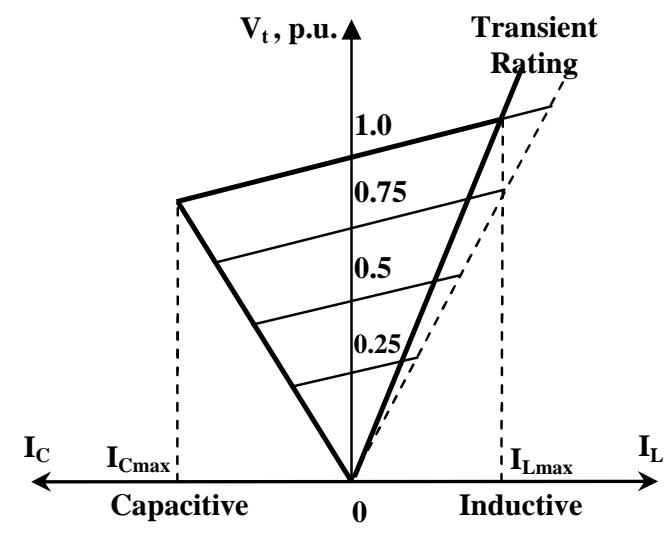

Fig. 4. V-I characteristic of the SVC

Once the maximum capacitive output limit of the SVC is reached, the SVC operates as a fixed capacitor. At this condition, the maximum obtainable capacitive current decreases linearly and the generated reactive power decreases as a square of the system voltage. Thus, the minimum value of the capacitive reactance is when the SVC reaches its maximum capacitive rating limit. Any further reduction in voltage will only reduce the output rating retaining a constant reactance. Midpoint voltage control of transmission lines is one of SVC applications. It has been proven that the midpoint of the transmission line is the best location for such a shunt VAR compensator because the voltage sag along uncompensated transmission line is a maximum at that point. Therefore, by providing reactive power compensation at the midpoint of the line, the voltage profile of the line can be improved and, thus, its power carrying capacity can be increased [4], [5]. 


\section{Impact of the Midpoint SVC on the Performance of the Generator Distance Phase Backup Protection}

The results obtained from the time-domain simulations of the system under study are analyzed with respect to the following points:

The relationship between the measured impedance and the generator loading

The injected current of a midpoint SVC is a function of both the transmission line loading and length. The transmission line loading is directly related to the generator output MVA while the line length affects its series impedance. Therefore, the measured impedance by the generator distance phase backup protection relay varies with the fault location in a nonlinear manner.

The midpoint SVC response to unsymmetrical phase faults

A Midpoint SVC used for voltage control applications is designed with a balanced three-phase firing circuit. During unsymmetrical transmission line phase faults (i.e. line-to-line faults), the faulted phases experience a severe voltage collapse compared to the healthy phase. The midpoint SVC would, however, still provide equal compensation for all the three phases. This could result in a significant increase in the voltage of healthy phase.

C. Effect of the midpoint SVC control circuit transient response during faults on the relay operating time

The transient response of the midpoint SVC control circuit during three-phase and line-to-line faults causes the impedance trajectory seen by the generator distance phase backup protection relay (21) to take longer time to converge to a new steady-state value. This results in delaying the operating time of the relay.

D. Relay (21) performance during faults and the definition of the percentage error

In order to illustrate the adverse impact of the midpoint SVC on the performance of the generator distance phase backup protection relay (21), the error measured in the relay performance is defined as follows:

$$
\text { Error, } \%=\frac{\left|Z_{\text {SVC in service }}\right|-\left|Z_{\text {SVC disabled }}\right|}{\left|Z_{\text {SVC disabled }}\right|} \times 100
$$

Where $\mathrm{Z}$ is the measured impedance by the relay.

E. Calculating the capability curve of the generator under study

The capability curve of the generator under study was calculated and plotted at the rated terminal voltage $(23 \mathrm{kV})$ in the P-Q plane as it has been explained in Section III, and is shown in Fig. 5.

$F$. The coordination between generator capability curve $(G C C)$ and the generator distance phase backup protection relay (21) 
In order to perform the coordination the generator capability curve (GCC) is converted from the P-Q plane to the R-X plane and plotted with the characteristic of the generator distance phase backup protection relay (21) as it has been explained in Section III, and is shown in Fig. 6

G. Maximum setting of generator distance phase backup protection relay (ZGCC).

The first factor which should be defined is the maximum setting of the generator distance phase backup protection relay (21) in order to maintain the coordination with the generator capability curve (GCC) for different generator loadings. The maximum setting of the generator distance phase backup protection relay is selected at $90 \%$ of the generator load impedance at MTA $=85^{\circ}$ which yields $\mathrm{ZGCC}=27.54$.

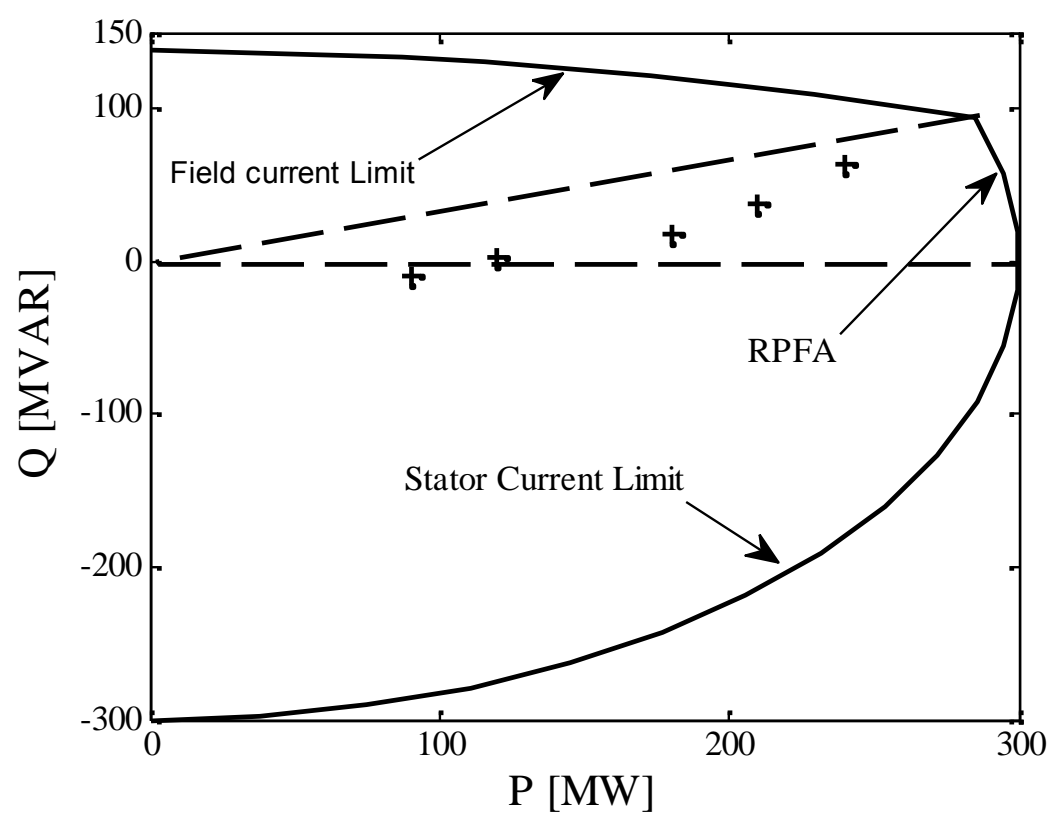

Fig. 5. Capability curve for the generator under study. 


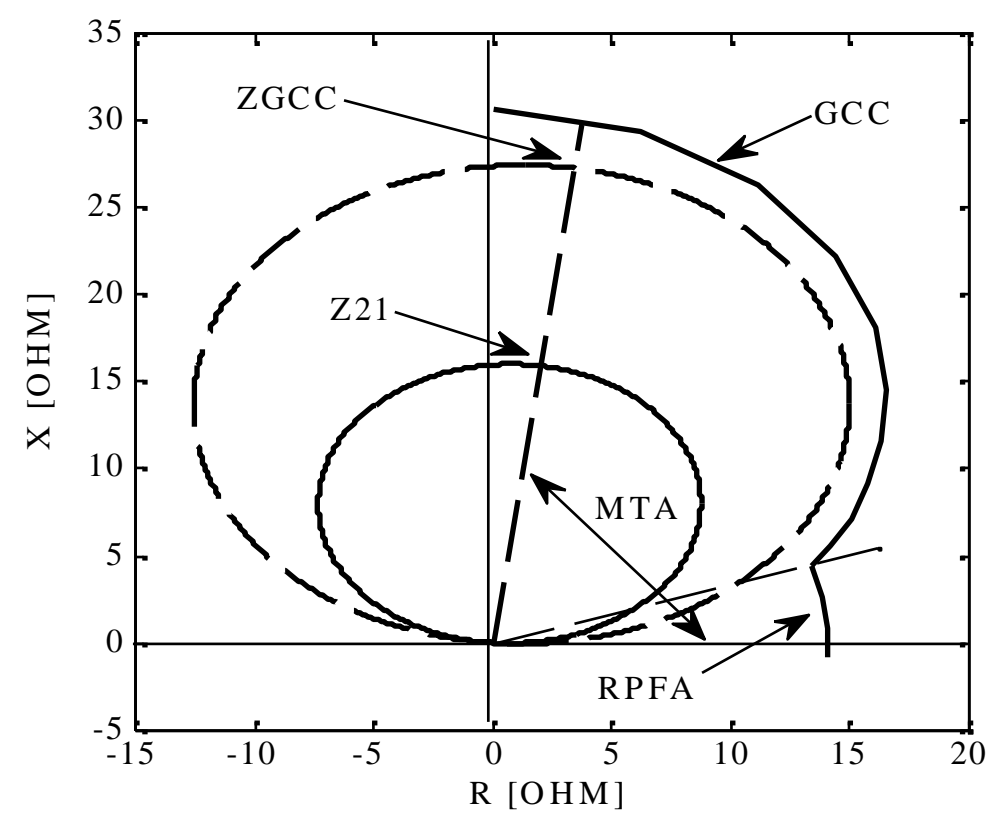

Fig. 6. Coordination between generator distance phase backup protection and the generator capability curve.

Figs. 7 and 8 illustrate the effect of the midpoint SVC on the performance of the generator distance phase backup protection relay (21) during three-phase and line-toline faults at different generator loadings and fault locations. The following observations are worth noting.

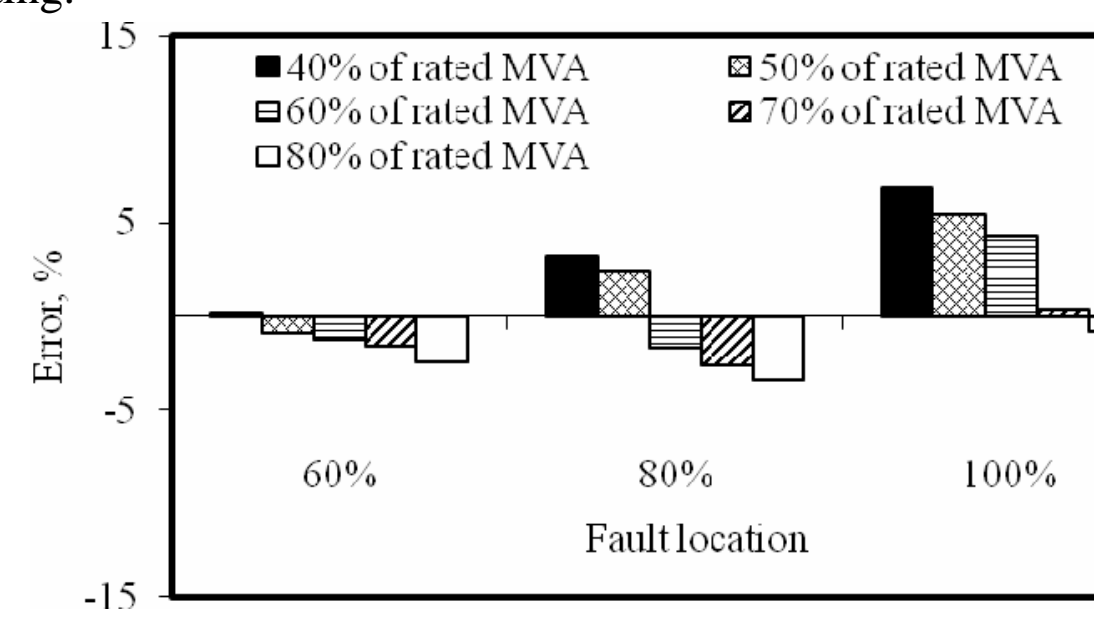

Fig. 7. Percentage error of the distance phase backup relay due to SVC for a threephase fault. 


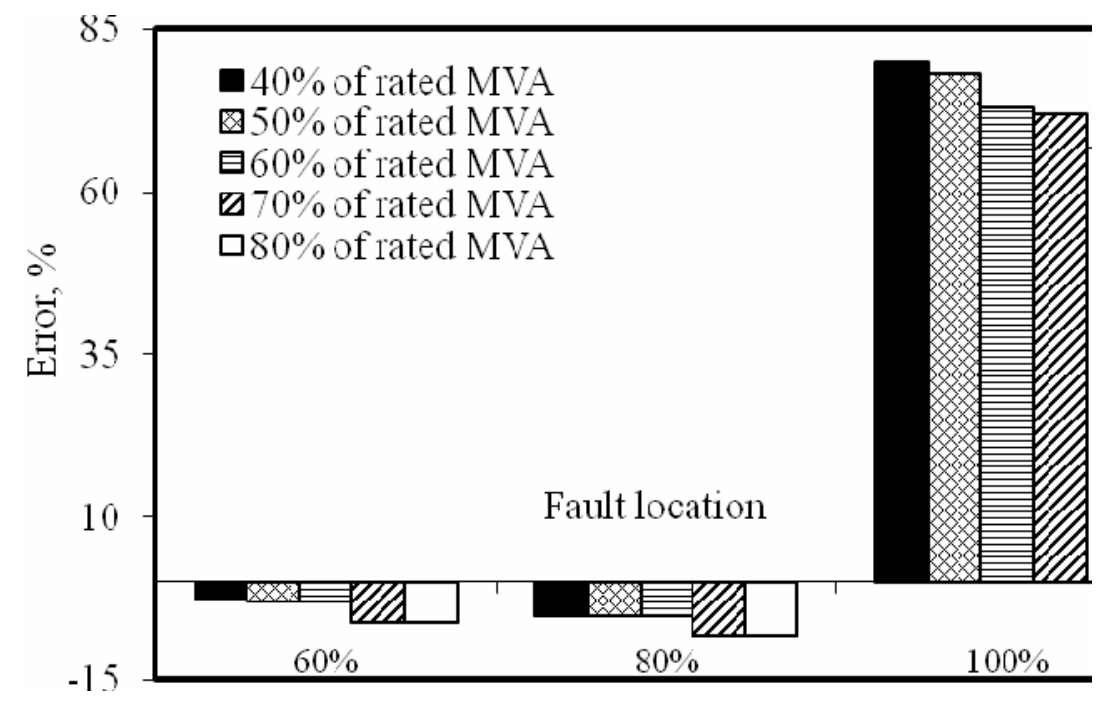

Fig. 8. Percentage error of the distance phase backup relay due to the SVC for a line-toline fault.

\section{1- Performance of the relay element}

According to the error value, the relay performance can be classified into the following categories:

- True underreach (TUR) (the relay does not pickup for both types of faults): where the fault is inside the protected zone and the measured impedance with the midpoint SVC is in service is greater than the relay reach (the error is greater than $66.72 \%$ ).

- False underreach (FUR) (the relay picks up for a fault with a time delay): where the fault is inside the protected zone and the measured impedance with the midpoint SVC is in service is less than the relay reach. (The error is positive and less than $66.72 \%$ ).

- True overreach (TOR): where the relay picks up for both types of faults outside the protected zone and the midpoint SVC is in service. (This case, however, does not exist for the system under study).

- False overreach (FOR): (relay picks up with a time delay) where the fault is inside the protected zone and the measured impedance with the midpoint SVC is in service is less than the measured impedance when the SVC is disabled (the error is negative).

- A time delay in the relay element response has occurred for both fault types (during FOR). This time delay increases as the fault location varies from the midpoint of the line to its end at bus B. The maximum time delay $(71.5 \mathrm{msec})$ was obtained for a threephase faults during a FOR. The maximum number of TUR cases (5 cases) was obtained for line-to-line faults at relay reach. Table (1) shows the severest cases of time delay in the operating time and (TUR) of the generator distance phase backup protection relay (21) for both line-to-line and three phase faults at the relay reach. 
TABLE (1): Time Delays in the Operating Time of Relay (21) and TUR during Threephase and Line-to-line Faults

\begin{tabular}{|c|c|c|c|}
\hline & \multicolumn{2}{|c|}{ Fault Location at the relay reach } \\
\hline & & $\begin{array}{c}\text { Line-to-Line } \\
\text { fault }\end{array}$ & $\begin{array}{c}\begin{array}{c}\text { Three-phase } \\
\text { fault }\end{array} \\
\text { fall }\end{array}$ \\
\hline \multirow{5}{*}{$\begin{array}{c}\text { Generator } \\
\text { Loading } \\
\text { (\% of rated } \\
\text { MVA) }\end{array}$} & $40 \%$ & \multirow{5}{*}{ TUR } & $71.5 \mathrm{msec}$ \\
\hline & $50 \%$ & & $64 \mathrm{msec}$ \\
\hline & $60 \%$ & & $30 \mathrm{msec}$ \\
\hline & $70 \%$ & & -- \\
\hline & $80 \%$ & & -- \\
\hline
\end{tabular}

2- Effect of the generator loading

- For both three-phase and line-to-line faults, the highest relay error occurred at the lowest generator loading condition considered in the investigations of this paper, namely $40 \%$. This highest error is $6.97 \%$ and $79.87 \%$ for the cases of three-phase and line-to-line faults respectively.

- For the same fault location, the response of the midpoint SVC to the variation in the generator loading may cause the generator distance phase backup protection relay (21) to experience true underreach (TUR), false underreach (FUR), and false overreach (FOR) cases.

3- Effect of the fault type

-As the midpoint SVC control circuit operates normally in a balanced mode (injecting three-phase balanced current), the severest impact of the SVC was obtained during lineto-line faults, at all generator loadings and fault locations.

- The maximum number of true underreach (TUR) cases ( 5 cases) was obtained for lineto-line faults; at the end of the line for all the generator loadings.

- For three-phase faults, no TUR cases were obtained. This is due to the fact that the SVC supplies very limited capacitive compensation when its terminal voltage is at low values as illustrated in Fig. 4. On the other hand FUR and FOR cases were obtained for different generator loadings.

4- Effect of the fault location

- For both of three-phase and line-to-line faults, the highest error was obtained at the end of the transmission line.

- The midpoint SVC has no impact on the generator distance phase backup protection relay (21) for faults occurring from the generator terminals to the midpoint of the transmission line regardless of the generator loading or the type of fault.

5- Impact of SVC on the coordination between function 21 relay and GCC 
For all the generator loadings, fault types and fault locations, and according to parts $\mathrm{E}$ to $\mathrm{G}$, the coordination between the generator distance phase backup protection (function 21) and the generator capability curve under the impact of a midpoint SVC was also investigated. Results of this investigation showed that for the particular system under study the midpoint SVC has no impact on such coordination for all the considered operating conditions. The impact of the midpoint SVC on the performance of the generator distance phase backup protection (function 21 relay) at the relay reach which has been discussed above in details is illustrated graphically in the R-X plane in Figs. 9 and 10 for both three-phase and line-to-line faults.

\section{Conclusion}

In this paper, investigations were carried out to explore the impact of midpoint SVC on the generator distance phase backup protection (21). The results of these investigations have shown that the midpoint SVC has an adverse effect on such protection. Such an impact varies according to the fault type, the fault location, and the generator loading. It has been found for the system under study that the reach of the generator distance phase backup protection relay (21) is 16.1 at MTA of $85^{\circ}$. With the presence of the midpoint SVC, it has been shown that this reach has been exceeded at some generator loadings and fault locations. This highlights the need for the search of new methods to achieve better performance when FACTS controllers are in service. The authors are presently utilizing the Support Vector Machines technique for achieving a better performance for the generator phase backup protection and the results are very encouraging. This will be the subject of a future paper.

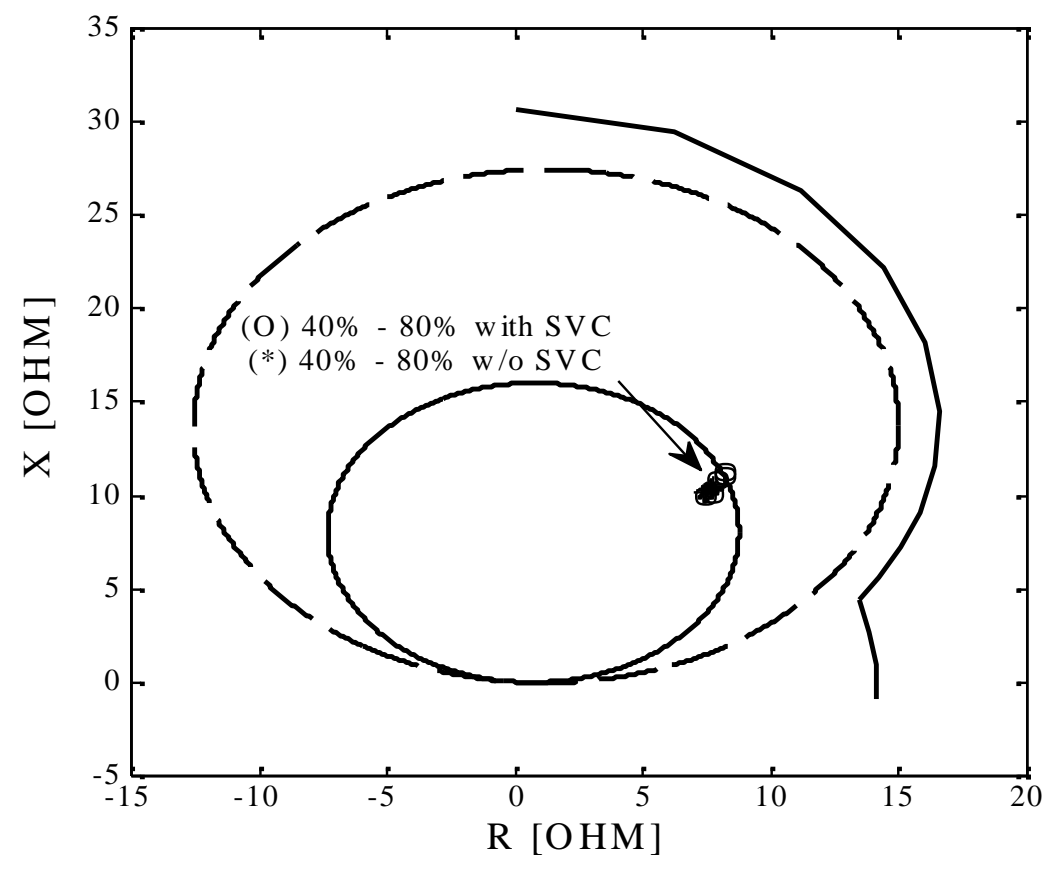


Fig. 9. Impact of midpoint SVC on the performance of the generator distance phase backup protection for three-phase faults at the relay reach (the percentages are the generator loading).

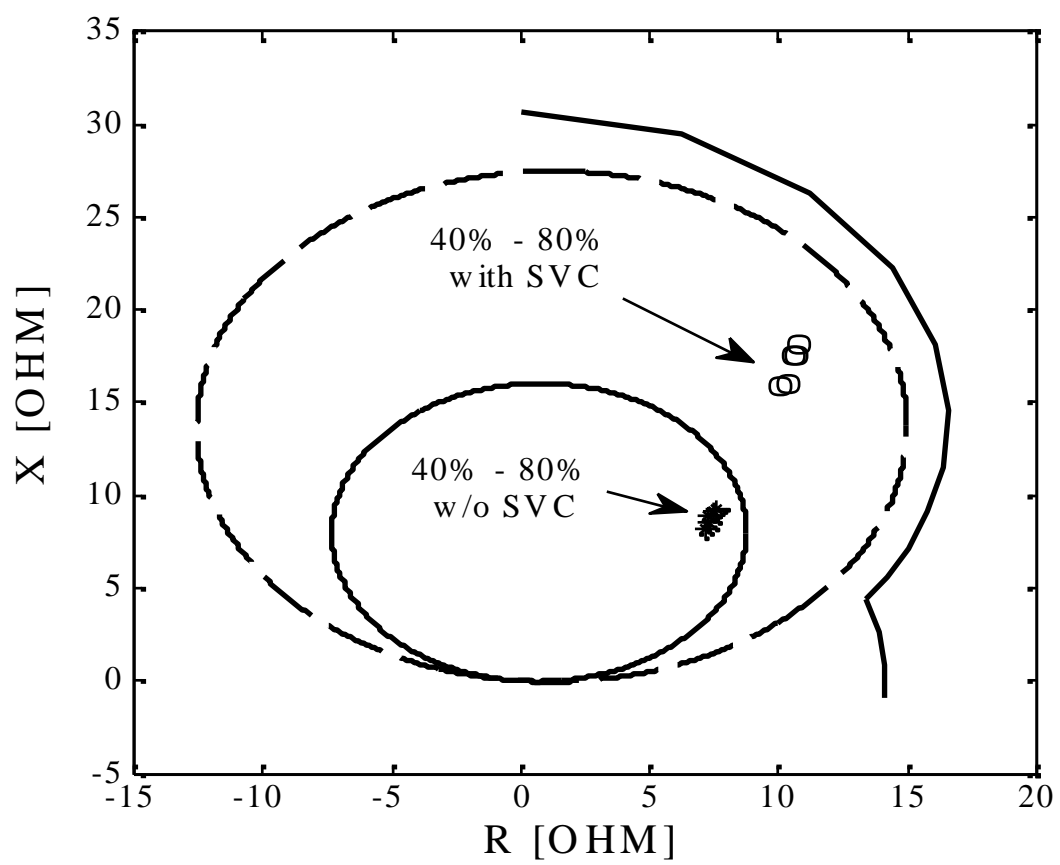

Fig. 10. Impact of midpoint SVC on the performance of the generator distance phase backup protection for line-to-line faults at the relay reach (the percentages are the generator loading).

\section{References}

[1] C.J. Mozina, M. Reichard, Z. Bukhala, "Coordination of Generator Protection with Generator Excitation Control and Generator Capability," Working Group J-5 of the Rotating Machinery Subcommittee of the Power System Relay Committee, in Proc. IEEE Power Engineering Society General Meeting, Tampa, USA, June 2007, pp. 1-17.

[2] S. Patel, K. Stephan, "Performance of Generator Protection during Major System Disturbances," IEEE Trans. on Power Del., vol. 19, no 4, pp. 1650-1662.October 2004.

[3] D. Tziouvaras, "Relay Performance during Major System Disturbances," in Proc. Protective Relay Engineers, 2007. 60th Annual Conference, College Station, TX, 27-29 March 2007, pp. 251-270.

[4] N.G. Hingorani and L. Gyugyi, Understanding FACTS Concepts and Technology of Flexible AC Transmission Systems, John Wiley \& Sons, November 1999.

[5] R.M. Mathur and R.K. Varma, Thyristor-based FACTS Controllers for Electrical Transmission Systems, Wiley-IEEE Press, February 2002. 
[6] K. El-Arroudi, G. Joos and D.T. McGillis, " Operation of Impedance Protection Relays with the STATCOM," IEEE Trans. on Power Del., vol.17, no. 2, pp. 381387, April 2002.

[7] A. Kazimi, S. Jamali and H. Shateri, "Effects of STATCOM on Distance Relay Tripping Characteristic," in Proc. IEEE PES Transmission and Distribution Conference and Exhibition: Asia and Pacific, Dalian, China, 2005, pp.1-6.

[8] S. Jamali, A. Kazemi, and H. Shateri," Effects of STATCOM on Measured Impedance by Distance Relay in Double Circuit Transmission Line," in Proc. IET 9th International Conference on Developments in Power System Protection, DPSP 2008, March 2008, pp. 540-545.

[9] T. S. Sidhu, R.K. Varma, P.K. Gangadharan, F.A. Albasri and G.R. Ortiz, "Performance of Distance Relays on Shunt-FACTS Compensated Transmission Lines," IEEE Trans. on Power Del., vol. 20, no. 3, pp.1837-1845, July 2005.

[10] F.A. Albasri, T. S. Sidhu, R.K. Varm, "Impact of Shunt-FACTS on distance protection of Transmission Lines, ” in Proc. Power Systems Conf., Clemson, SC, March 14-17, 2006.

[11] F.A. Albasri, T.S. Sidhu, R.K. Varma, "Performance Comparison of Distance Protection Schemes for Shunt-FACTS Compensated Transmission Lines," IEEE Trans. on Power Del., vol.22, no. 4, pp.2116-2125, October 2007.

[12] M. Khederzadeh "The Impact of FACTS device on the digital multifunctional protective relays", Transmission and Distribution conference and Exhibition, Asia pacific. IEEE/PES, Oct. 2002, Vol.3, pp.2043-2048.

[13] PSCAD/EMTDC User's Manual, Manitoba HVDC Research Centre, 2003.

[14] IEEE Std. C37.102, “IEEE Guide for AC Generator Protection,” 2006.

[15] D. Reimert, Protective Relaying for Power Generation Systems, CRC Press, 2006.

[16] P. Kundur, Power System Stability and Control, McGraw Hill, 1994.

[17] Charles Mozina, "Power Plant Protection and Control Strategies for Blackout Avoidance," in Proc. IEEE PS Advanced Metering, Protection, Control, Communication, and Distributed Resources Conference, March 14-17, 2006, pp. 200-218.

[18] W. Elmore, Protective Relaying Theory and Applications, CRC Press, $2^{\text {nd }}$ Edition, 2004.

\section{Appendix}

Generator: Rating $=300$ MVA, Rated Voltage $=23 \mathrm{kV}$,

$\mathrm{Xd}=\mathrm{j} 1.15$ p.u., $\mathrm{Xq}=\mathrm{j} 0.75$ p.u, $\mathrm{RPFA}=17.64^{\circ}$

Function 21 relay setting $=16.1 \angle 85^{\circ} \Omega$

Generator Step Up (GSU) Transformer:

$300 \mathrm{MVA}, 23 \mathrm{kV} \quad / 230 \mathrm{kV}, \mathrm{Yg}$, Leakage reactance $=\mathrm{j} 0.1$ p.u.

Transmission Line: $300 \mathrm{Km}, z_{1}=0.51 \angle 85.98^{\circ} \quad \mathrm{km}$ 
Proceedings of the $7^{\text {th }}$ ICEENG Conference, 25-27 May, 2010

Midpoint STATCOM: Type: 12-Pulse

Coupling transformer: $100 \mathrm{MVA}, 11 / 230 \mathrm{kV}, \mathrm{Xt}=\mathrm{j} 0.1$ p.u.

\section{$\underline{\text { Biographies }}$}

Mohamed Elsamahy obtained the B.Sc. and M.Sc. degrees in electrical engineering from the Military Technical College (M.T.C), Cairo, Egypt, in 1997 and 2003, respectively. He is currently pursuing the Ph.D. degree in Electrical Engineering in the Department of Electrical and Computer Engineering at the University of Saskatchewan, Saskatoon, SK, Canada.

Sherif O. Faried (S'88-M'88-SM'00) received the B.Sc. and M.Sc. degrees from Ain Shams University, Cairo, Egypt, in 1979 and 1984, respectively, and the M.Sc. and $\mathrm{Ph} . \mathrm{D}$. degrees from the University of Saskatchewan, Saskatoon, SK, Canada, in 1988 and1993, respectively, all in electrical engineering. He is currently a Professor of electrical engineering in the Department of Electrical and Computer Engineering, University of Saskatchewan. His current research interests include power system dynamics, control, reliability, protection, and power quality.

Tarlochan Singh Sidhu (SM'94-F'04) received the B.E.(Hons) degree from the Punjabi University, Patiala, India, in 1979, and M.Sc. and Ph.D. degrees from University of Saskatchewan, Saskatoon, SK, Canada, in 1985 and 1989, respectively. Currently he is Chair of Department of Electrical and Computer Engineering and Professor and Hydro One Chair in Power Systems Engineering at the University of Western Ontario, London, ON, Canada. His areas of Research interest include power system protection, monitoring, and control. Dr. Sidhu is a Fellow of the IEEE, Fellow of the Institution of Electrical Engineers of the U.K., Fellow of the Institution of Engineers, India, a Professional Engineer registered in the Province of Ontario, and a Chartered Engineer in the U.K.

Ramakrishna Gokaraju graduated in Electrical and Electronics Engineering in 1992 from Regional Engineering College, Trichy, India. He obtained M.Sc. and Ph.D. degrees in Electrical \& Computer Engineering from the University of Calgary, Calgary, Canada in 1996 and 2000, respectively. He is currently an Associate Professor at the University of Saskatchewan, Canada. His areas of interest include Power System Control \& Protection, and Applications of Intelligent Systems to Power Systems. 